\title{
Applicability of Tanaka \& Johnston Analyssis and Prediction of New Equation for Contemporary Nepalese Sample
}

\author{
Dr Jyoti Dhakal,' Dr Rabindra M Shrestha,2 Dr Sujita Shrestha \\ 'Lecturer, ${ }^{2}$ Asso Prof, Department of Orthodontics, 3Lecturer, \\ Department of Community \& Public Health Dentistry \\ Kantipur Dental College, Kathmandu, Nepal
}

Correspondence: jyotidhakal@yahoo.com

\section{ABSTRACT}

Objective: To examine applicability of Tanaka \& Johnston prediction in Nepalese sample.

Materials \& Method: A total of 100 samples of the age ranging from 14-24 years were selected for the measurement of mesio-distal widths of mandibular permanent incisors, and maxillary and mandibular permanent canines and premolars. Descriptive statistics was calculated and paired t-test was carried out to find the difference between predicted and actual values of canine and premolar mesio-distal widths. The linear regression equation was performed to develop new equation for Nepalese sample.

Result: Mean differences were observed in actual and predicted values between the present study and the reports of Tanaka \& Johnston. Coefficient of correlation was found for maxilla, $r=0.52$ and mandible, $r=0.51$.

Conclusion: The equations and charts used for other ethnic sample do not accurately predict for Nepalese sample. The linear regression equation developed in this study can be used for orthodontic treatment for Nepalese patients.

Key words: arch length discrepancy, mesio-distal width, mixed dentition, prediction

\section{INTRODUCTION}

An important aspect of orthodontic diagnosis in the mixed dentition is the determination of tooth size-arch length discrepancy. The operator who provides care for children and adolescent should be able to assess the developing malocclusion and probably reduce the irregularity in adult dentition.

It is believed that most of the malocclusions start during mixed dentition period, and also early treatment is becoming popular in the contemporary orthodontic practice.' Space analysis during mixed dentition is a fundamental step to determine any tooth size-arch length discrepancy. In such cases it is important to predict the deficiency in arch space in advance before the permanent posterior teeth erupt for evaluating whether treatment will involve space maintenance, serial extraction, space regaining, proximal stripping etc. $^{1-5}$

There are three popular methods for predicting the mesio-distal widths of unerupted permanent canine and premolars.

1. Direct measurement from radiograph with or without the use of a prediction formula, ${ }^{1,6}$

2. Use of prediction chart based on measurements of other erupted permanent teeth, 7.8

3. Combination of previous two methods. 9,10

The most accurate prediction is achieved by using both radiograph and dental cast. However, in a developing country like ours the availability of $x$-ray service and quality of available radiograph is questionable. Due to these limitations non-radiographic technique i.e. the use of dental cast alone would be the choice. 
Tanaka \& Johnston ${ }^{8}$ used north-western European natives for predicting the size of the unerupted canines and premolars by using the mesiodistal widths of the four permanent mandibular incisors. Because of its simplicity researchers have investigated the applicability of Tanaka \& Johnston analysis in various ethnic groups, however the accuracy of these predictions are in question when applied to a population of different ethnic group. ${ }^{11-15}$

The present study was designed to evaluate the applicability of Tanaka \& Johnston method in predicting the size of unerupted permanent canine and premolars of the Nepalese samples.

\section{MATERIALS AND METHOD}

A total of 100 study models of 50 male and 50 female samples were chosen from the Department of Orthodontics, Kantipur Dental College \& Hospital, Kathmandu. The age of the subjects ranged from 1424 years. The samples were selected according to the inclusion criteria of Class I molar and canine relation, presence of all permanent teeth in each arch with or without second and third molars, teeth without anomalies in number, shape, size and structure. All samples were native Nepalese. None of the subject had undergone orthodontic treatment. Teeth with fractures, proximal caries, proximal restorations and attrition were excluded. The study models were obtained from alginate impression and were poured in dental stone. Sliding vernier caliper with an accuracy of $0.1 \mathrm{~mm}$ was used to measure the tooth size. The mesio-distal dimension of the teeth were measured according to the method described by Moorrees \& Reed. ${ }^{16}$ The maximum dimension of the tooth crown between the contact points on its proximal surface was measured. The study was conducted during March 2013.

Sum of the mesio-distal widths of following groups of teeth were calculated;

a) Mandibular incisors

b) Maxillary canines and premolars

c) Mandibular canines and premolars

The present study used Tanaka \& Johnston equation's constant ' $a$ ' to predict unerupted mesio-distal width of canines and premolars of both maxillary and mandibular arches.
To predict values for maxillary arch; half of the mesiodistal widths of lower incisors were added to constant 'a' $(11 \mathrm{~mm})$. And, to predict values for mandibular arch; half of the mesio-distal widths of lower incisors were added to constant ' $a$ ' (10.5 mm).

Tanaka \& Johnston equations are as follows;

Maxillary left and right permanent canine and both premolar width; $Y=11.0+0.5 \mathrm{X}$

Mandibular left and right permanent canine and both premolar width; $Y=10.5+0.5 \mathrm{X}$

Where, $Y$ is the sum of permanent canine and both premolars of each side and $X$ is the sum of the width of the four mandibular permanent incisors.

Data were analyzed using SPSS Version 17.0. Descriptive statistics including mean, standard deviation and range were calculated and paired Student's t-test was done to compare the mean of actual and predicted mesio-distal dimensions of canines and premolars of both maxillary and mandibular arches.

Linear regression equations; $Y=a+b X$ was used to calculate equation of the sum of the maxillary and mandibular canine and premolars based on the sum of mandibular incisors, where ' $Y$ ' represents the predicted combined mesio-distal width of the canine and premolars (dependent variable), and ' $X$ ' represents the measured mesio-distal width of the mandibular incisors (independent variable). Values ' $a$ ' and 'b' are constant.

\section{RESULT}

Descriptive statistics of the summation of right and left canines and premolars of both maxilla and mandible are presented in Table 1. The mean, standard deviation and range of the actual and predicted values of the Nepalese sample are presented. The mean predicted values derived from Tanaka \& Johnston equation is slightly higher than the actual mean value of canine and premolars for both upper and lower arches.

Paired t-test between the actual and predicted values of canine and premolars widths shows no significant difference (Table 2). 
Table 1: Descriptive statistics for the summation of the actual and predicted mesio-distal widths

\begin{tabular}{|l|l|l|c|c|}
\hline (in mm) & Mean & SD & Maximum & Minimum \\
\hline$\Sigma$ LI & 21.34 & 1.37 & 24.50 & 18.75 \\
\hline$\Sigma$ ACPMU & 20.07 & 1.06 & 22.63 & 17.38 \\
\hline$\Sigma$ ACPML & 19.65 & 1.12 & 22.88 & 17.00 \\
\hline$\Sigma$ PCPMU & 21.71 & 0.81 & 23.75 & 20.00 \\
\hline$\Sigma$ PCPML & 21.23 & 0.80 & 23.25 & 19.50 \\
\hline
\end{tabular}

(LI-lower incisor, ACPMU-actual canine premolar width upper, ACPML-Actual canine premolar width lower, PCPMU-predicted canine premolar width upper, PCPML-predicted canine premolar width lower)

Table 2: Paired sample t-Test for the difference between the mean values of actual sums of mesio-distal widths

\begin{tabular}{|l|c|c|c|c|}
\hline & Mean difference & SD $(\mathbf{m m})$ & $95 \% \mathbf{C l}(\mathbf{m m})$ & p-value \\
\hline Maxilla & 0.17 & 1.24 & $2.01-1.31$ & $.001^{*}$ \\
\hline Mandible & 0.18 & 1.28 & $1.94-1.21$ & $.001^{*}$ \\
\hline
\end{tabular}

SD-standard deviation, Cl-confident interval, *statistically significant

Based on regression equation for prediction of mesio-distal widths of canine and premolars (dependent variables) using mesio-distal widths of the mandibular incisors (independent variables); correlation coefficient (r), Standard error of estimation (SEE) and the 95\% confidence intervals (CI) were depicted (Table 3). Depending on these values the equations were as follows:

Maxilla: $Y=11.43+0.40(X)$

Mandible: $Y=10.30+0.43(X)$

Table 3: Regression parameters for prediction of mesio-distal widths

\begin{tabular}{|l|c|c|c|c|l|}
\hline & $\begin{array}{c}\text { Correlation coefficient } \\
\text { (r) }\end{array}$ & \multicolumn{2}{|c|}{ Constant } & $\begin{array}{c}\text { Standard error of } \\
\text { estimate (SEE) }\end{array}$ & $\begin{array}{l}\text { Coefficient of } \\
\text { determination }\left(\mathbf{r}^{2}\right)\end{array}$ \\
\hline Maxilla & 0.52 & 11.43 & 0.40 & 0.91 & 0.27 \\
\hline Mandible & 0.51 & 10.30 & 0.43 & 1.00 & 0.26 \\
\hline
\end{tabular}

\section{DISCUSSION}

Prediction of mesio-distal widths of canine and premolars during late primary dentition or early mixed dentition is critical period for prevention and interception of developing malocclusion. ${ }^{15}$ Among various mixed dentition analyses; regression equation based on the measurement of erupted permanent teeth are most commonly used. The present study was conducted to evaluate the applicability of Tanaka \& Johnston equation for native Nepalese sample. Tanaka \& Johnston prediction of the widths of unerupted teeth in a population provides inaccurate estimates due to racial and ethnic variations of tooth size. ${ }^{3-15,17}$ Studies show that Tanaka \& Johnston prediction overestimates mesio-distal widths of the teeth, this finding was apparent in cases of Asian Americans, ${ }^{4}$ Senegalese, ${ }^{21}$ black South Africans, ${ }^{11}$ and Saudi Arabians. ${ }^{14}$ Present study also shows the overestimation of both maxillary and mandibular buccal segment. The use of overpredicted or underpredicted values influence the diagnosis and treatment planning. 
Table 4: Comparison of regression constant values among various population groups

\begin{tabular}{|c|c|c|c|c|c|c|}
\hline \multirow{2}{*}{$\begin{array}{l}\text { Population } \\
\text { group }\end{array}$} & \multirow{2}{*}{ Arch } & \multirow{2}{*}{$\begin{array}{l}\text { Correlation } \\
\text { coefficient (r) }\end{array}$} & \multicolumn{2}{|c|}{ Constant } & \multirow{2}{*}{$\begin{array}{l}\text { Standard error of } \\
\text { estimate (SEE) }\end{array}$} & \multirow{2}{*}{$\begin{array}{l}\text { Coefficient of } \\
\text { determination ( } r 2)\end{array}$} \\
\hline & & & $a$ & b & & \\
\hline \multirow{2}{*}{ Thai ${ }^{15}$} & $\mathrm{mx}$ & 0.60 & 11.87 & 0.47 & 0.84 & 0.36 \\
\hline & md & 0.64 & 10.30 & 0.50 & 0.82 & 0.41 \\
\hline \multirow{2}{*}{$\begin{array}{l}\text { Black } \\
\text { American }{ }^{17}\end{array}$} & $m x$ & 0.62 & 11.93 & 0.44 & - & 0.38 \\
\hline & md & 0.70 & 9.93 & 0.52 & - & 0.49 \\
\hline \multirow{2}{*}{$\begin{array}{l}\text { Negro } \\
\text { population }{ }^{18}\end{array}$} & $m x$ & 0.65 & 10.18 & 0.52 & 0.87 & 0.42 \\
\hline & md & 0.07 & 8.30 & 0.64 & 0.94 & 0.49 \\
\hline \multirow{2}{*}{$\begin{array}{l}\text { Hong Kong } \\
\text { Chinese }^{19}\end{array}$} & $m x$ & 0.69 & 7.97 & 0.66 & 0.68 & 0.42 \\
\hline & md & 0.77 & 8.82 & 0.58 & 0.61 & 0.60 \\
\hline \multirow{2}{*}{$\begin{array}{l}\text { South } \\
\text { Arabian }^{14}\end{array}$} & $m x$ & 0.65 & 7.20 & 0.63 & - & 0.42 \\
\hline & md & - & 8.60 & 0.55 & - & 0.49 \\
\hline \multirow{2}{*}{ Senegalese ${ }^{20}$} & $\mathrm{mx}$ & 0.68 & 9.87 & 0.53 & 0.71 & 0.46 \\
\hline & md & 0.73 & 5.67 & 0.70 & 0.81 & 0.54 \\
\hline \multirow{2}{*}{ Pakistani²1 $^{2}$} & $m x$ & 0.59 & 10.52 & 0.48 & 0.82 & 0.35 \\
\hline & md & 0.65 & 8.56 & 0.54 & 0.79 & 0.42 \\
\hline \multirow{2}{*}{$\begin{array}{l}\text { Tanaka \& } \\
\text { Johnston }\end{array}$} & $m x$ & 0.63 & 10.41 & 0.51 & 0.86 & 0.40 \\
\hline & md & 0.65 & 9.18 & 0.54 & 0.85 & 0.42 \\
\hline \multirow{2}{*}{$\begin{array}{l}\text { Nepalese } \\
\text { (present study) }\end{array}$} & $\mathrm{mx}$ & 0.51 & 11.43 & 0.40 & 0.91 & 0.27 \\
\hline & md & 0.52 & 10.30 & 0.43 & 1.00 & 0.26 \\
\hline
\end{tabular}

mx-maxillary, md-mandibular

The correlation coefficient derived for Nepalese samples between the buccal segments of each arch and the mandibular incisors are lesser than that of the Hong Kong, ${ }^{19}$ black Americans, ${ }^{17,18}$ Senegalese ${ }^{21}$ and the Tanaka \& Johnston values ${ }^{8}$ (Table 4). In our study correlation coefficient $(r)$ is above 0.50 for both maxilla and mandible, which shows that these regression equations can be placed into good clinical orthodontic use. The coefficient of determinants $\left(r^{2}\right)$, which indicates predictive accuracy of regression equation is lower in the present study as compared to other studies.

The standard error of estimate (SEE) in the present study is higher compared to previous studies. However it has been found that; lower the SEE, better the predictive value. Lesser ' $r$ '' and higher SEE values in the present study may be due to smaller sample size and due to mixed ethnic samples within the Nepalese population.

In comparison with other studies, constant ' $b$ ' is slightly lower in our study. Constant ' $b$ ' of 0.5 value facilitates practical application of the prediction equation. Constant ' $a$ ' value for mandible and maxilla appears to overlap with the values of other studies. $15,17-20$ Constant ' $a$ ' of 11.43 for maxilla and 10.30 for mandible are similar to that of the Thai and black American population. ${ }^{15,17,18}$

Further investigation with larger sample size considering ethnic diversity among Nepalese population is required to collect more representative data. It would be more constructive and appropriate to undertake further evaluation of the prediction values, particularly to reduce the prediction error.

\section{CONCLUSION}

The regression equations proposed in the present study are able to predict the widths of the maxillary and mandibular permanent canine and premolars. These simplified equations are easy and practical to use and require no sophisticated software or instrument. However, due to possible influence of racial and ethnic difference in different population groups; the proposed values must be tested in other groups to confirm its applicability and consistency. 


\section{REFERENCES}

1. Proffit WR, Fields H W. Contemporary Orthodontics. 3rd Ed. St. Lovis: Mosby Inc; 2000: 165-70.

2. Huckaba GW. Arch size analysis and tooth size prediction. Dent Clin North Am 1964; 11: 431-40.

3. Smith HP, King DL, Valencia R. A comparison of three methods of mixed-dentition analyses. J Pedod 1979; 3: 291-302.

4. Lee- Chan S, Jacobson BN, Chwa KH, Jacobson JS. Mixed Dentition for Asian-Americans. Am J Orthod Dentofac Orthop 1998; 113: 293-99.

5. Bishara SE, Jakobsen JR. Comparison of two non radiographic methods of predicting permanent tooth size in the mixed dentition. Am J Orthod Dentofac Orthop 1998; 113: 573-6.

6. Nance HN. Limitation of orthodontic treatment. Mixed dentition diagnosis and treatment. Am J Orthod Oral Surg 1947; 33 : 177223.

7. Moyers RE. Handbook of Orthodontics. 4th ed. Chicago, III:Year Book; 1988:235-9.

8. Tanaka MM, Johnston LE. The prediction of the size of unerupted canines and premolars in a contemporary orthodontic population. J Am Dent Assoc. 1974; 88:798-801.

9. Hixon EH, Oldfather RE. Estimation of the sizes of unerupted cuspid and bicuspid teeth. Angle Orthod 1958; 28: 236-40.

10. Staley RN, Hoag JF. Prediction of the mesio-distal tooth width of maxillary permanent canines and premolars. Am J Orthod 1978; 73: 169-77.

11. Schirmer UR, Wiltshire WA. Orthodontic probability tables for black patients of African descent: Mixed dentition analysis. Am J Orthod Dentofac Orthop 1997; 112:545-51.

12. Bishara SE, Jacobsen JR, Abdullah EM, Garcia AF. Comparisons of mesio-distal and bucco-lingual crown dimensions of the permanent teeth in 3 populations from Egypt, Mexico, and the United states. Am J Orthod Dentof Orthop 1989; 96: 416-22

13. Mengal N, Afzal A. Mixed dentition analysis for Pakistani population J Surg Pak 2004; 9(1):10-14.

14. Al-Khadra BH. Prediction of the size of unerupted canines and premolars in a Saudi Arab population. Am J Orthod Dentofac Orthop 1993; 104(4):369-372.

15. Jaroontham J, Godfrey K. Mixed dentition space analysis in a Thai population. Eur J Orthod 2000; 22(2):127-134.

16. Moorrees CFA \& Reed RB. Correlations among crown diameters of human teeth. Arch oral Biol 1965; 9:685-97.

17. Frankel HH, Benz EM. Mixed dentition analysis for black Americans. Pediatr Dent 1986; 8:226-30.

18. Ferguson FS, Macko DJ, Sonnenberg EM, Shakun ML. The use of regression constants in estimating tooth size in Negro population. Am J Orthod 1978; 73: 68-71.

19. Yuen KK, Tang EL, So LL. Mixed dentition analysis for Hong Kong Chinese. Angle Orthod 1998; 68(1):21-8.

20. Mbow k. Mixed dentition analysis in a Senegalese population: Elaboration of prediction tables. Am J Orthod Dentof Orthop 2003; 124:178-83.

21. Aneel K Bherwani, Mubassar Fida. Development of a prediction for the mixed dentition in Pakistani sample. Am J Orthod Dentof Orthop 2011; 140:626-32. 